\title{
A Cytomorphological Study of Spectrum of Male Chest Wall Lesions Including Breast in Fine Needle Aspirates
}

\author{
Pooja Agarwal ${ }^{1}$, Prashant Prakash ${ }^{2 *}$, Gunjan Agarwal ${ }^{1}$ and Arsh Gupta ${ }^{3}$ \\ ${ }^{1}$ Department of Pathology, S.N. Medical College, Agra, India \\ ${ }^{2}$ Department of Medicine, S.N. Medical College, Agra, India \\ ${ }^{3}$ RML Inst. of Medical Sciences, Lucknow, India
}

\begin{abstract}
Background: This study was undertaken to study the spectrum and cytomorphological features of male chest wall lesions including breast. A total of 50 cases presenting in a year were studied.

Methods: Aspiration was carried out in all the male patients presenting with chest wall and breast lesions. All smears were stained with MGG and their cytomorphology studied. Ziel-Nelson staining was done on necrotic aspirates to look for AFB.

Result: Maximum numbers of cases (16) were seen in 21-30 yrs of age group while only 1 case was encountered in 8th decade. Most common diagnosis was lipoma (28\%) followed by gynaecomastia $(20 \%)$, inclusion cyst $(18 \%)$, necrotizing inflammation $(12 \%)$, acute/ subacute inflammation( $08 \%)$, spindle cell lesion( $04 \%)$, adenocarcinoma (04\%) and high grade NHL (02\%). The cases, for which histologic confirmation could be sought, showed $100 \%$ cytohistologic correlation.
\end{abstract}

Conclusion: It was concluded that fine needle aspiration cytology of male chest wall lesion is a useful, safe and diagnostic procedure with high rate of histological correlation.

Keywords: Chest Wall, Gynaecomastia, Male Breast.

\section{Introduction}

The chest wall is a complex system that provides rigid protection to the vital organs such as the heart, lungs, and liver; stability to arm and shoulder movement; and flexibility to aid in the functional process of respiration. The chest wall comprises the muscles, bones, joints, and soft tissues situated between the neck and the abdomen. Many pathologic processes may involve the chest wall like congenital and developmental anomalies, inflammatory and infectious diseases, soft tissue tumors, bone tumors and other malignancies. Diagnostic modalities for chest wall lesions include X-ray, C.T, M.R.I, F.N.A.C. and biopsy. By F.N.A.C., we can avoid unnecessary surgery in patients with benign lesions. If it is difficult or impossible to get material using a needle, then patient might undergo an open biopsy. A study of male chest wall lesions including breast, to the best of our knowledge, is not available in literature although few studies on chest wall lesions of both males and females ${ }^{[1]}$ and male breast lesions ${ }^{[2,3,4,5]}$ have been published earlier. Scattered case reports of tuberculosis of chest wall, ${ }^{[6]}$ tuberculous involvement of ribs ${ }^{[7]}$ and sternum, ${ }^{[8]}$ chondrosarcoma of chest wall ${ }^{[9]}$ and desmoids tumors ${ }^{[10]}$ are also available in literature. So this study was undertaken to study the spectrum and cytomorphological features of male chest wall lesions including breast.

\section{Materials \& Methods}

This study was conducted in the Department of Pathology over a period of one year. All the male patients presenting with chest wall and breast lesions were included in the study. A total of 50 cases were studied. Aspiration was carried out in all the male patients presenting with chest wall and breast lesions using a 22 or 23 gauge needle attached to a $20 \mathrm{ml}$ disposable syringe. The needle was introduced into the target and suction was applied by retracting the syringe plunger to the $1-2 \mathrm{ml}$ mark. The needle was moved back and forth four to five times in same plane to ensure minimal bleeding. The aspirated material was expressed onto the slides and the material was smeared by pressing with another slide. Smears were air-dried; methanol fixed and stained with May-Grunwald Giemsa (MGG). ZiehlNeelsen staining was also done in necrotic aspirates.

\section{Result}

The smears were assessed for adequacy and cytomorphological features like arrangement of cells, nuclear features, presence or absence of myoepithelial cells, bipolar bare nuclei, mitotic figures, stromal component and inflammatory cells, if any. The aspirate was considered adequate if the cellular elements were sufficient for rendering a diagnosis. The maximum numbers of cases 
(16) were present between 21-30 yrs of age group while only 1 case was seen in $8^{\text {th }}$ decade (TABLE 1 ). The adequacy was obtained in 48 aspirates out of 50(96\%), 2 aspirates were inadequate as they comprised only of blood or few inflammatory cells. Out of 48 cases, the most common diagnosis was lipoma (14) followed by gynaecomastia (10) and inclusion cyst (9). Necrotising inflammation was seen in 6 cases, among them 4 were AFB positive and 2 were AFB negative. 4 cases were of acute/subacute bacterial inflammation. 2 cases showed spindle cell cytology, one of which proved to be dermatofibrosarcoma protuberans on histology. 3 cases of malignant lesions were observed out of which 1 case was of high grade Non-Hodgkin's Lymphoma and 2 cases were of breast adenocarcinoma (TABLE 2).

\section{Cytomorphological Features and Histologic} Correlation: Smears from lipoma consisted mainly of fragments of mature adipose tissue, a few single fat cells and fat droplets. The fat cells were large and had abundant empty cytoplasm and a small eccentric dark nucleus (Figure 1). 12 cases were excised and sent for histopathology. All of them were reported as lipoma.Smears from gynaecomastia were variably cellular, ranging from scanty to marked cellularity and there was bimodal pattern of stroma and epithelial cells in addition to single bare bipolar/oval nuclei in the background. 6 cases of gynaecomastia showed large flat monolayered sheets of epithelial fragments while in 4 cases epithelial fragments were seen in small monolayer sheets. Out of 10 cases 4 showed presence of finger like projections similar to fibroadenoma (Figure 2). Moderate nuclear variation and atypia was noted in 2 cases which can be allowed in the presence of benign bimodal pattern. Only 3 cases underwent excision. Histology corresponded to cytological diagnosis of gynaecomastia.

Aspirates from inclusion cyst showed a dirty background with high cellularity comprising of nucleate and anucleate squames (Figure 3). Keratinous material was seen in 2 cases but the amount was less compared with the cellular elements. 6 cases turned for surgery with $100 \%$ confirmation of cytological diagnosis. 6 cases showed necrosis out of which 4 cases also revealed the presence of granulomas. Smears from granulomatous lesions showed moderate cellularity with presence of epithelioid histiocytes which were present singly or in aggregates. Out of these 4 cases, 2 cases also showed the presence of Langhan's giant cells. 2 cases showed only necrotizing inflammation. 4 cases showed AFB positivity on Ziel-Nelson staining (Figure 4). 4 cases were of acute/subacute inflammation. Smears revealed numerous polymorphs, few lymphocytes, sparse macrophages and plasma cells. Coccal aggregates were seen in 2 cases (Figure 5). AFB was negative in all these cases.Smears from adenocarcinoma were highly cellular. Cells were round to oval, large, pleomorphic and were in clusters and sheets. Scattered cells and acini formation was also noted. Cytoplasm was scanty to moderate in amount and pale blue in colour. Nuclei were large, round to oval with membrane irregularity and marked pleomorphism; nucleoli were seen in both the cases. Myoepithelial cells were absent (Figure 6). The male breast carcinomas were distinguished on cytology from gynaecomastia on the basis of high cellularity, dyscohesive cell groups with anisonucleosis and membrane irregularity. Absence of bipolar bare nuclei is also an important clue. All the 2 cases underwent surgery and histology was consistent with the cytological diagnosis of adenocarcinoma. 2 cases were of Spindle cell neoplasm. Smears were moderately cellular. Cells were spindle shaped and were present singly as well in clusters and sheets. Cytoplasm was scant to moderate in amount and pale blue in color. Nuclei were plump spindle with high $\mathrm{N}: \mathrm{C}$ ratio, nucleoli were inconspicuous in most of the cells. 1 case turned out to be dermatofibrosarcoma protuberans (DFSP) on histology. Other case was lost on follow up (Figure 7).1 case was of high grade Non-Hodgkin's lymphoma. Smear was highly cellular and showed predominant population of monotonous intermediate round cells with very high $\mathrm{N}: \mathrm{C}$ ratio, prominent nucleoli, dense finely granular chromatin and high mitotic rate. Histology of this case could not be sought (Figure 8).

Table 1: Distribution of Cases According to Age Groups.

\begin{tabular}{|c|c|c|c|}
\hline S. No. & Age groups in yrs & No of cases & Percentage \\
\hline 1. & $1-10$ & 04 & 08 \\
\hline 2. & $11-20$ & 10 & 20 \\
\hline 3. & $21-30$ & 16 & 32 \\
\hline 4. & $31-40$ & 04 & 08 \\
\hline 5. & $41-50$ & 06 & 12 \\
\hline 6. & $51-60$ & 04 & 08 \\
\hline 7. & $61-70$ & 05 & 10 \\
\hline 8. & $71-80$ & 01 & 02 \\
\hline & Total & $\mathbf{5 0}$ & $\mathbf{1 0 0}$ \\
\hline
\end{tabular}


Table 2: Distribution According to Cytological Diagnosis.

\begin{tabular}{|c|c|c|c|c|}
\hline S. No. & Type of lesion & Lesion & No of cases & $\%$ age \\
\hline 1. & Inadequate aspirate & Only blood aspirated & 02 & $04 \%$ \\
\hline \multirow{6}{*}{2.} & \multirow{6}{*}{ Benign } & Lipoma & 14 & $28 \%$ \\
\hline & & Gynaecomastia & 10 & $20 \%$ \\
\hline & & Inclusion cyst & 09 & $18 \%$ \\
\hline & & Necrotising inflammation (1 was AFB positive) & 02 & $04 \%$ \\
\hline & & $\begin{array}{l}\text { Necrotising granulomatous inflammation ( } 3 \text { wereAFB } \\
\text { positive) }\end{array}$ & 04 & $08 \%$ \\
\hline & & Acute/subaute bacterial inflammation & 04 & $08 \%$ \\
\hline 3. & Spindle cell lesion & 01 was dermatofibrosarcoma protuberans. & 02 & $04 \%$ \\
\hline \multirow{3}{*}{4.} & \multirow{3}{*}{ Malignant } & High grade NHL & 01 & $02 \%$ \\
\hline & & Adenocarcinoma & 02 & $04 \%$ \\
\hline & & Total & 50 & $100 \%$ \\
\hline
\end{tabular}

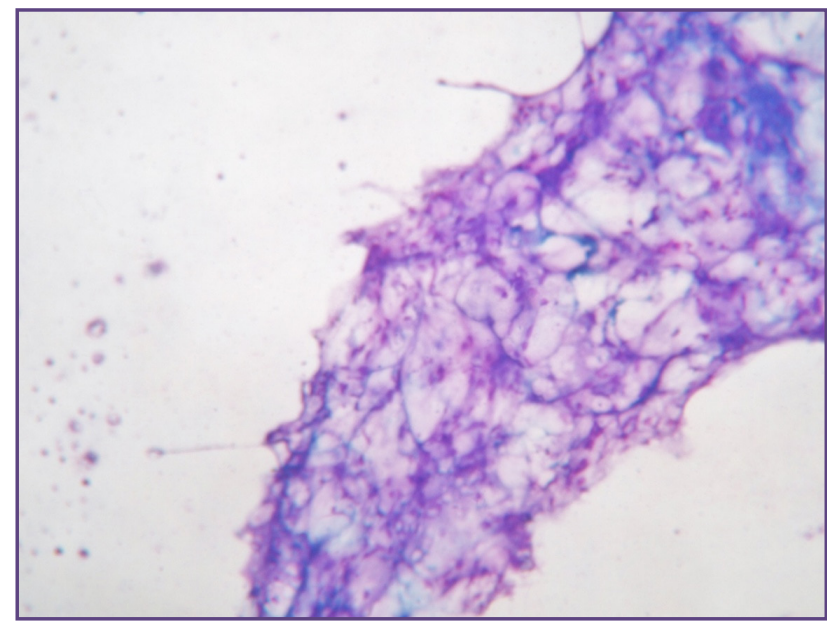

Fig.1: Lipoma: Mature adipose tissue along with stroma (MGG 10×10).

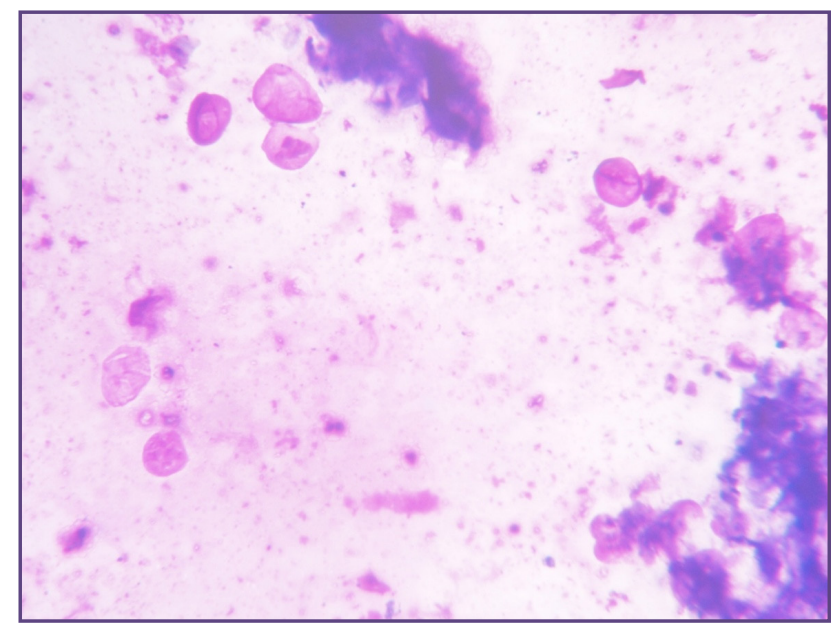

Fig. 3: Inclusion cyst showing presence of anucleate squames in a dirty background (MGG 10×10).

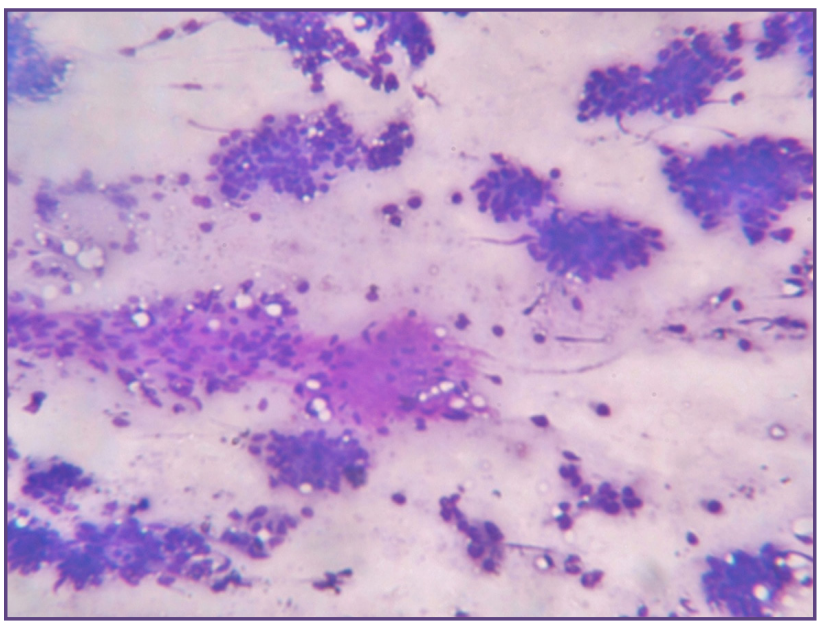

Fig. 2: Gynaecomastia: presence of stroma along with flat sheets of epithelial cells (MGG 10×10).

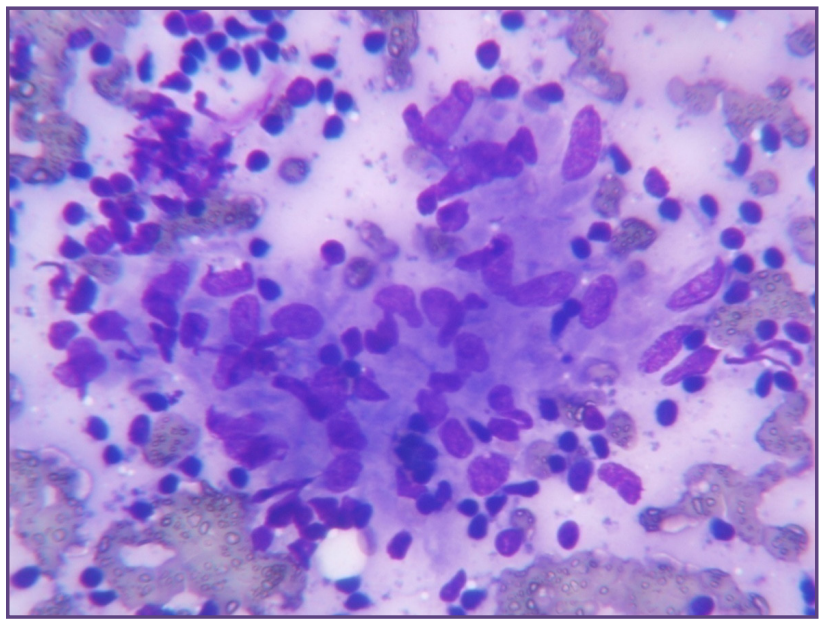

Fig. 4: Granulamatous inflammation (MGG 10×40). 


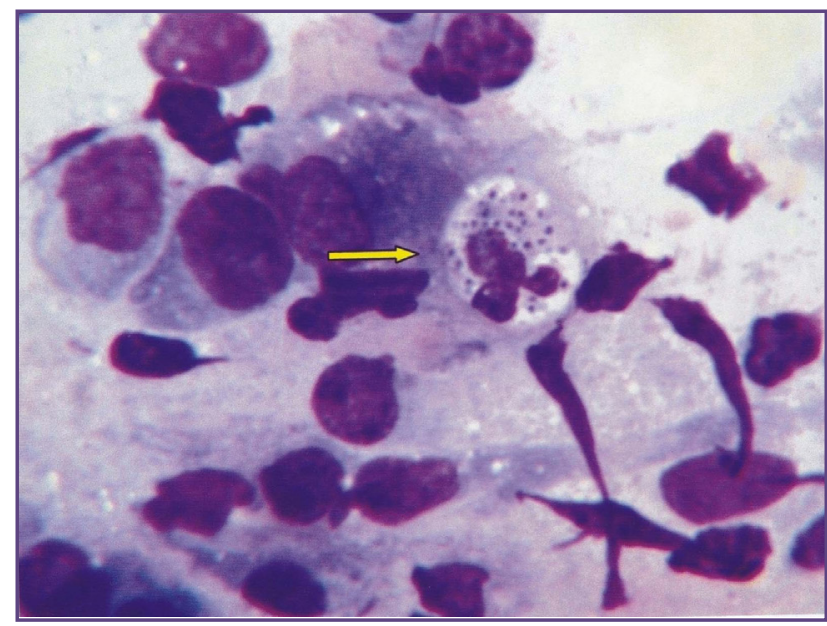

Fig. 5: Subacute inflammation showing coccal aggregates within neutrophil (MGG 10×100).

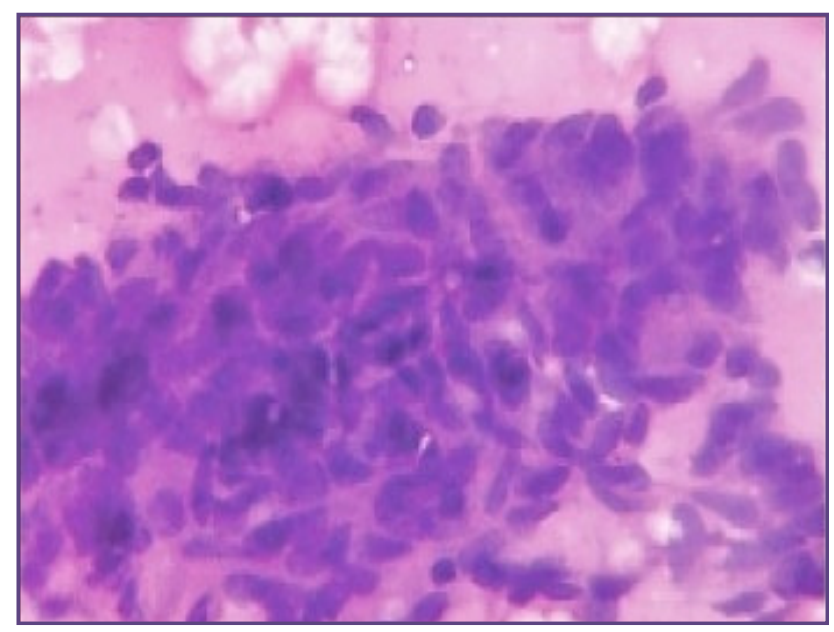

Fig. 7: Spindle cell neoplasm showing cluster of spindle cells (MGG 10×40).

\section{Discussion}

A total of 50 cases were aspirated and specific diagnosis could be rendered in 48 cases. The adequacy in the present study was $96 \%$. Goel A et $\mathrm{a}^{\left[{ }^{[1]}\right.}$ and Sneige $\mathrm{N}$ et $\mathrm{a}^{\left[{ }^{[1]}\right]}$ observed an adequacy rate of $91 \%$ and $92 \%$ respectively which was almost similar to present study. Singh R et al observed adequacy rate of $100 \%$ which was slightly higher than the present study. ${ }^{[2]}$ In the current study, specific diagnosis was rendered in 48 cases, of which 43 were non-malignant, 2 were spindle cell lesions and 3 were malignant. In our study, the percentage of non-malignant cases( $86 \%$ ) was fairly similar to that observed by Singh $\mathrm{R}$ et $\mathrm{al}^{[2]}(88.2 \%)$. The range reported in the literature for malignant diagnosis varied from $11.8 \%$ (Singh R et al ${ }^{[2]}$ to $36.1 \%$ (Goel A et al) ${ }^{[1]}$ and the range for non-malignant diagnosis varied from $55.5 \%$ (Goel A et al) ${ }^{[1]}$ to $88.2 \%$ (Singh R et al) ${ }^{[2]}$. In our study, the lower number of malignant cases could be due to

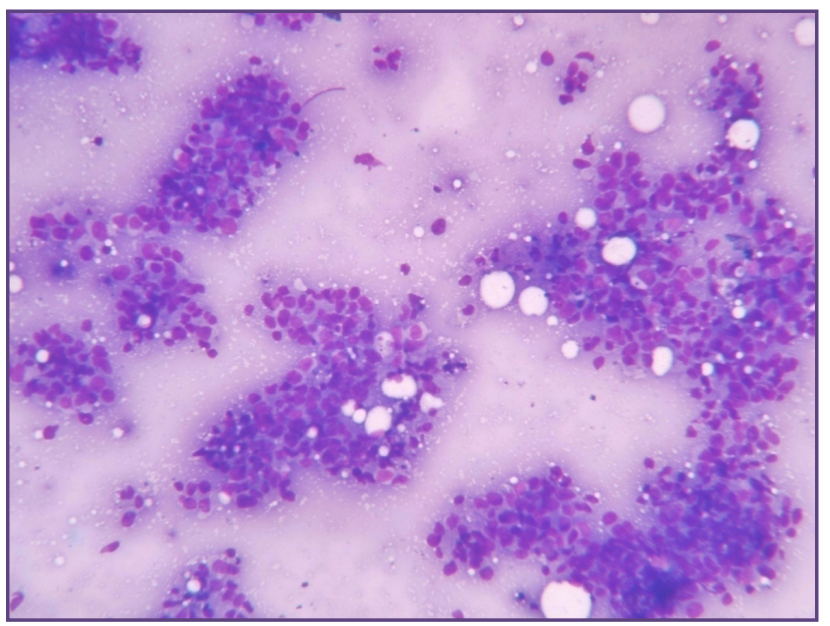

Fig. 6: Adenocarcinoma showing Acinii and sheets of malignant epithelial cells (MGG 10×10).

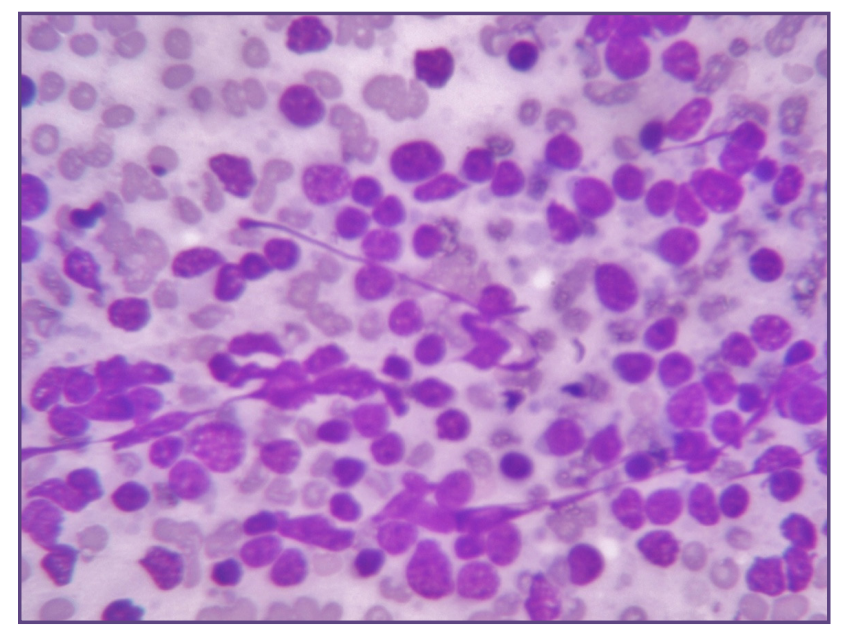

Fig. 8: High grade Non-Hodgkin's Lymphoma showing dispersed lymphoma cells (MGG 10×40).

smaller size as compared to other studies. The frequency of gynaecomastia (20\%) in the present study was significantly lower than that of Sniege $\mathrm{N}$ et $\mathrm{al}^{[11]}(70.3 \%)$ and Singh $\mathrm{R}$ et $\mathrm{al}^{[2]}(72.2 \%)$. This could be because they studied only male breast lesions while our study covered male chest wall lesions including breast. Goel A et $\mathrm{al}^{[1]}$ however did not encounter any case of gynaecomastia. Gynaecomastia results from increased estrogen activity or decreased androgenic activity or both. ${ }^{[12,13]}$ Causes of gynecomastia in later years may be: hormonallyactive tumors, cirrhosis, certain medications ${ }^{[14]}$ or idiopathic. Cytologic atypia was seen in smears with high cellularity. One important clue to the correct diagnosisis is epithelial cohesiveness in smears of gynecomastia, with presence of very few single atypical cells. The frequency of adenocarcinoma in present study was lower than that of Sniege $\mathrm{N}$ et al. ${ }^{[11]}$ Goel A et al and Singh $\mathrm{R}$ et al did not encounter any case of adenocarcinoma. 
[1,2] The cytomorphological features of adenocarcinoma were similar to that studied by Joan Cangiarella et al. ${ }^{[15]}$

Lipoma is a common soft tissue tumour at this site as was seen in our study. It comprised $28 \%$ of all lesions. Its incidence was higher than Goel A et $\mathrm{al}^{[1]}(16.7 \%)$ and Sniege $\mathrm{N}$ et $\mathrm{al}^{[11]}(1.5 \%)$. Singh $\mathrm{R}$ et al did not encounter any case of lipoma. Again this could be due to the fact Singh $\mathrm{R}$ et $\mathrm{al}^{[2]}$ studied only male breast lesions. The cytomorphological features of lipoma were similar to that studied by Mans Akerman et al. ${ }^{[16]}$ They also emphasized that for the diagnosis of lipoma it is important to make sure that sample is representative of the suspected tumour. Common soft tissue tumors encountered at this site are cutaneous leiomyomas, hemangioma, lymphangioma and fibrous lesions including nodular fasciitis and fibromatosis. We also encountered two cases of soft tissue tumors comprising of spindle cells one of which turned out to be dermatofibrosarcoma protuberans on histology.Among the soft tissue tumours of the chest wall, dermatofibrosarcoma protuberans (DFSP) is an uncommon entity. DFSP is a slow-growing, locally invasive but rarely metastasizing tumour. Our case also presented with recurrent chest wall mass after surgery. DFSP constitutes less than $0.1 \%$ of all malignancies and is slightly more frequent among males during early or mid-adult life.

\section{Conclusion}

It is thereby concluded that fine needle aspiration cytology of male chest wall lesion is a useful, safe and diagnostic procedure with a very high rate of cytohistologic correlation. Complications were minimal and in our study included only mild discomfort or mild pain during needle puncture.

\section{References}

1. Goel A, Gupta SK, Dey P, Radhika S,et al. Cytologic Spectrum of 227 Fine Needle Aspiration Cases of ChestWall Lesions. Diagn Cytopathol 2001; 24(6): 384-8.

2. Singh R, Anshu, Sharma SM, Gangane N.Spectrum of Male Breast Lesions Diagnosed by Fine Needle Aspiration Cytology. Diagn Cytopathol 2012; 40(2):113-7.
3. Pailoor K, Fernandes H, Murali KS. Fine Needle Aspiration Cytology of Male Breast Lesions - A Retrospective Study Over a Six Year Period. J Clin Diagn Res 2014;8(10):13-15.

4. Chide PM, Nayak S, Kumbhalkar D. Role of Fine Needle Aspiration Cytology in Male Breast Lesions. Int J Res Med Sci 2016;4(9):3945-3950.

5. Westend PJ, Jobse C. Evaluation of Fine Needle Aspiration Cytology of Breast Masses in Males. Cancer 2002;96(2):101104.

6. Gaude GS, Reyas AK. Tuberculosis of the Chest Wall Without Pulmonary Involvement. Lung India 2008;25(3):135-137.

7. Keny SJ. Tuberculosis of Ribs with Cold Abscess.JIACM 2014:15(2):137-8.

8. Vasa M, Ohikhuare C, Brickner L.Primary Sternal Tuberculosis Osteomyelitis: A Case Report and Discussion. Can J Infect Dis Med Microbiol 2009;20(4):181-184.

9. Capps E, Shiller M, Konduri K. Chest Wall Chondrosarcoma. Proc(Bayl Univ Med Cent) 2009;22(4):362-365

10. Kabiri EH, Aziz SA, Maslout AE, Benosman A. Desmoid Tumours of the Chest Wall. European Journal of CardioThoracic Surgery 2001;19(5):580-583.

11. Sneige N, Holder PD, Katz RL, Fanning CV et al. Fine Needle Aspiration Cytology of the Male Breast in a Cancer Center. Diagn Cytopathology 1993;9(6):691-697.

12. Carlson HE. Approach to the Patient with Gynecomastia. J Clin Endocrinol Metab. 2011;96:15-21

13. Johnson RE, Murad MH. Gynecomastia: Pathophysiology, Evaluation, and Management. Mayo Clin Proc. 2009;84:1010-5

14. Rahmani S, Turton P, Shaaban A, Dall B. Owerview of gynecomastia in the modern era and the Leeds Gynaecomastia Investigation algorithm. Breast J. 2011;17:246-55.

15. Cangiarella J, Waisman J, Simsir A. Cytologic Findings with Histologic Correlation in 43 cases of Mammary Intraductal Adenocarcinoma Diagnosed by Aspiration Biopsy. Acta Cytol 2003;47:965-72.

16. Akerman M, Carlen B, Pomanski H A et al. Core Needle Biopsy Performed by the Cytopathologist. A Technique to Complement Fine -Needle Aspiration of Soft Tissue and Bone Lesions. Cancer (cancer cytopathol) 2005;105:229-39. 